\title{
A diáspora de Maria: relações sincréticas e culturais entre Nossa Senhora, Kianda e Nzuzu em O outro pé da sereia, de Mia Couto.
}

\section{The diaspora of Mary: syncretic and cultural relations between Holy Mary, Kianda and Nzuzu in O outro pé da sereia, by Mia Couto.}

Resumo: Nativa da Galileia, Maria tornar-se-ia o maior ícone feminino do cristianismo. Contudo, séculos depois, sua imagem cruza os mares, dentro de caravelas portuguesas, como 'patrona da colonização'. Maria torna-se diaspórica e desemboca frente a outras divindades, criando uma relação sincrética com estas - um mesmo registro de relação com o sagrado. A partir da colonização portuguesa na África, os colonizadores utilizando a autoridade religiosa, impuseram a fé cristã aos bantos, e geraram assim uma crença híbrida e sincrética. No romance $O$ outro pé da sereia (2006), Mia Couto mostra como esse sincretismo uniu a África portuguesa desde a colonização até os dias de hoje, e como Nossa Senhora, a grande mãe cristã, também passou por esse processo, tornando-se, no romance, as deusas das águas africanas. Nossa proposta é analisar este sincretismo entre a Virgem Maria, Kianda, a sereia banto e Nzuzu, a deusa dos rios moçambicanos. Nossa análise versará sobre de que forma o sincretismo subverte as relações entre colonizadores e colonizados e ao mesmo tempo resgata identidades e valores profundos do sujeito (pós-) colonial.

Palavras-chave: Sincretismo. Literatura africana. Religiosidade.

Abstract: Mary of Galille would become the biggest female icon of Christianity. However, centuries later, her image crosses the seas, inside the Portuguese caravels as the 'patron saint of colonization'. Mary becomes diasporic and with other deities creates a syncretic relation with them - the same register of the relation with the sacred. From the Portuguese colonization in Africa, the colonizers using religious authority to impose the Christian faith to the Bantu people generated a hybrid and syncretic belief. In the novel O outro pé da sereia (2006), Mia Couto shows how this syncretism united the Portuguese Africa since colonization times to present days, and how Our Lady, the great Christian Mother also underwent this process, becoming in the novel the goddess of African waters. The aim of the article is to analyze this syncretism between the Virgin Mary, Kianda, the Bantu mermaid and Nzuzu, the Mozambican goddess of rivers. The analysis will focus on how the syncretism subverts the relationship between colonizers and colonized, while rescues identities and deep values of (post)-colonial people.

Keywords: Syncretism. African literature. Religiosity.

\footnotetext{
" Doutorando em Estudos Literários pela Universidade Estadual de Londrina (UEL). Especialista em Religião e Religiosidades nas literaturas pós-coloniais. E-mail: <silvinhoparadiso@hotmail.com>.
} 


\section{Considerações iniciais}

Do grego synkretismós, reunião de ideias ou de teses de origens díspares, amálgama de doutrinas ou concepções heterogêneas, o sincretismo baseia-se no fato da mistura religiosa, muito comum nas sociedades colonizadas. A própria teologia católica crê que a alma humana é naturaliter syncretista (BOFF, 1994, p.158). Todavia, foi com o encontro colonial entre a população escrava oriunda das terras africanas e a classe jesuítica da Igreja que o sincretismo tomou corpo, fazendo-se presente no imaginário de várias nações colonizadas por Portugal.

Aproximadamente, mais de quatro milhões de negros africanos cruzaram o Atlântico em uma diáspora insana, a fim de sustentar a colonização imperialista e cristã. Esses escravos traziam as lembranças de Angola, Congo, Moçambique e outras diferentes regiões da África e, consequentemente, suas bagagens culturais.

A palavra sincretismo é estritamente utilizada com foco religioso; diferencia-se então de termos como miscigenação e hibridismo, por exemplo. $\mathrm{O}$ "sincretismo, como é comumente entendido e como a própria etimologia da palavra mostra, representa a fusão de elementos de dois ou mais sistemas religiosos, podendo significar uma alteração significativa da estrutura básica de um dos sistemas ou de ambos". (MAGALHÃES, 1998, p.57). Crê-se que essa alteração da estrutura dos sistemas é o que polemiza o sincretismo, pois este, muitas vezes, gera a dupla militância religiosa, condenada severamente por religiosos cristãos, como, por exemplo, os jesuítas e missionários, já que a visão destes é unívoca frente à pluralidade religiosa do mundo africano.

Uma das formas de sincretismo, segundo Magalhães, é quando há "fusão de elementos da tradição cristã com os de religião africana. Nesse caso, os adeptos desta religião se sentem, em muitos casos, pertencentes a ambos os sistemas religiosos" (MAGALHÃES, 1998, p.58) - como é o caso do personagem Nimi Nsundi, em $O$ outro pé da sereia.

Magalhães (1998, p.54) ainda revela que o "sincretismo é um status teológico de difícil aceitação", que tenta suprimir, superar e criticar as divergências e as práticas religiosas não reconhecidas pela normatividade, isto é, pela religião hegemônica. O sincretismo é, então, um fato possível pela existência de um mesmo registro de relação com o sagrado, uma mesma sintonia religiosa. (BRUMANA; MARTINEZ, 1991, p.288). Esta sintonia pode se 
revelar de três modos distintos: teológico (no romance, Nossa Senhora, Kianda e Nzuzu são apresentadas como intercessoras junto a um Ser Superior), cultural (a tarefa funcional delas: Nossa Senhora e as Sereias são mães e mulheres), e social (todas servem a um patronato de grupos ou irmandades), resultado de um processo sincrético dividido em fases, como acomodação e assimilação.

Diz-se acomodação quando uma religião de dominados se adapta à religião dos dominadores, seja como estratégia de sobrevivência, seja como modo de resistência. (BOFF, 1994, p.159). Tal processo é o mais comum, e é chamado de acomodação, pois cabe ao "vencido" acomodar signos, festas e elementos rituais da religião do dominador. Como explicita Iza Chaim:

Tomava corpo, neste contexto, a ideia de que os deuses do povo vencedor subjugariam e se apropriariam do território, corpo e mentes da população vencida, submetendo e extinguindo as divindades relacionadas a ela. (CHAIM, 2003, p.43).

A assimilação é a consequência dessa fase, quando o indivíduo já não separa os elementos. O sincretismo no mundo colonial propõe resolver uma situação de "conflito cultural" (VALENTE, 1977, p.11), isto é, o sincretismo evita a negação da divindade ou aceitação plena de outras, mas as assimila. Entretanto, é uma das estratégias mais significativas do mundo colonial, já que subverte [in]conscientemente o sagrado do opressor e subjetifica o sagrado do oprimido: "O povo vencido, por sua vez, reagiria num processo de retaliação que colocaria a responsabilidade de todas as suas penúrias nos deuses do povo vencedor, vendo-os como entidades de cunho negativo". (CHAIM, 2003, p.43).

Para entendermos a funcionalidade do sincretismo no romance de Mia Couto, segue a fábula de $O$ outro pé da sereia.

\section{O outro pé da sereia (2006), de Mia Couto}

Mia Couto nasceu António Emílio Leite Couto, em uma colônia branca portuguesa, no dia 5 de julho de 1955, na cidade da Beira, Moçambique, durante o ainda período colonial. É atualmente um dos maiores nomes da literatura africana em língua portuguesa. Seus romances e poemas foram publicados em mais de 22 países e traduzidos para vários idiomas. Filho de uma família híbrida de emigrantes portugueses, Mia Couto teve uma infância diferente: "uma infância de viver no meio de negros, brincar com eles, os meus amigos, 
as pessoas que eu posso referenciar", revela (CHABAL, 1994, p.275). Muito dessa cultura mestiça de Moçambique é evidenciado em seus romances. Mia Couto vê que sua escrita é moçambicana, híbrida e anti-imperialista, já que essa construção identitária o acompanhou durante a juventude. Couto fez parte, sendo um dos fundadores, da Liga dos Estudantes Moçambicanos Antiimperialistas (CHABAL, 1994, p.279), além de pertencer a dois mundos: o africano e o europeu (CHABAL, 1994, p.276), isto é, ser híbrido. Tem orgulho de desenvolver uma literatura africana pós-colonial, mesmo não sendo negro: "Eu não reivindico que sou um africano completo. Não, eu sou uma pessoa misturada, eu sou moçambicano mas com toda uma carga de diversidade eu não estou mascarado de negro - não tenho tribo". (CHABAL, 1994, p.289. Grifo meu).

Em seu nono romance, O outro pé da sereia (2006), o enredo gira em torno de uma imagem de Nossa Senhora da Graça, o centro de uma trama dividida em dois momentos históricos, ligados por questões étnicas, religiosas e de destino familiar. Em 2002, dez anos depois dos acordos de paz entre governo e forças rebeldes, Moçambique é um país em recuperação. Um pastor e sua mulher, Mwadia Malunga, encontram uma imagem de Nossa Senhora nas margens de um rio da pequena localidade de Antigamente. A partir daí, saem em busca de uma resposta - o que fazer? Mwadia e seu marido Zero vão em busca do curandeiro Lázaro Vivo. O curandeiro revela que eles conspurcaram uma divindade do rio e correm grande perigo. Mwadia decide então voltar a Vila Longe, onde deixara a família, para abrigar a estátua. Curiosamente, esta é a imagem de Nossa Senhora que segue, em 1560, com o jesuíta Dom Gonçalo da Silveira, ao partir de Goa, na Índia, para converter ao cristianismo o imperador do Reino do Ouro, ou Monomotapa, situado na região fronteiriça entre os atuais Zimbábue e Moçambique.

A imagem de Nossa Senhora é chamada pelos escravos da nau portuguesa de Kianda, a sereia deusa das águas; e os africanos a tratam por Nzuzu, rainha das águas doces. É neste jogo de identidades, dessas três "santas" mulheres, que se desvela o sincretismo: resultado da diáspora.

\section{Sincretismo: as várias faces da mesma divindade em $O$ outro pé da sereia}

A religião dos dominadores aqui colocada pode ser lida como catolicismo romano e, mais precisamente, o missionarismo jesuítico, que num 
primeiro momento proclama o Evangelho cristão, reafirmando a identidade da religião e assim "convidando" à conversão. Após essa fase da chegada dos missionários aos povos não-europeus é que se inicia o processo de sincretismo (BOFF, 1994, p.174). Os fenômenos sincréticos envolvendo santos católicos e divindades africanas foram iniciados pelos próprios jesuítas e não pela população autóctone, como em geral é divulgado. Os jesuítas utilizavam o "teatro pedagógico" a fim de explicar a doutrina da Igreja, adaptando os mitos africanos (e indígenas) aos dogmas católicos, incentivando assim o sincretismo religioso. Até porque a escolha de um santo para perpetuar o signo de uma divindade nativa baseou-se em alguns aspectos dos respectivos seres, como cores, gênero, elemento, função e mito, por exemplo. Assim, era improvável que o nativo conhecesse suficientemente a biografia de um santo católico a fim de revestir sua divindade; ao contrário dos religiosos que, estudados, sabiam quais santos poderiam ser identificados com quais divindades.

Contudo, o sincretismo acabou servindo mais ao subalterno que a seu mestre, pois em muitos casos a conversão "real" não acontecia, e a tentativa de aculturação transformava-se em um fenômeno de resistência e preservação da cultura africana. Assim, quando passaram por Angola, na tentativa de converter a população negra, os jesuítas contribuíram para que as deusas aquáticas sincretizadas com a Virgem Maria se perpetuassem nessa ideia. Nsundi, o escravo "convertido", assimilou perfeitamente o sincretismo, mas entre as duas divindades que viviam na imagem de Maria (a própria Virgem Maria e Kianda, a deusa banto), Nsundi escolhe Kianda, anulando a identidade mariana, enquanto que os habitantes de Moçambique escolhem Nzuzu, enegrecendo Maria, a "mãe de Deus", subvertendo assim o discurso cristão.

No romance de Mia Couto, O outro pé da sereia, o deslocamento da Virgem Maria inicia-se na Índia. Certa vez, no carregamento do barco às portas da Igreja de Nossa Senhora da Penha de França, em Goa, na tentativa de salvar a imagem que tombara das mãos de Padre Antunes caindo no rio, Nsundi, o escravo, se joga e a "salva". Porém, o escravo alerta Dom Gonçalo que a Santa se jogara por vontade própria e revela os motivos da conclusão: "Essa Senhora, eu já conheço, na minha terra chamam de Kianda". (COUTO, 2006, p.52). Aqui se revela que em sua terra natal, Angola, já havia manifestações sincréticas entre o culto cristão e o culto tradicional.

A desmedida devoção de Nimi Nsundi ao culto da imagem comovia os clérigos, que imaginavam ali um sucesso de conversão. Todavia, o narrador 
onisciente revela: "Mal ele [Dom Gonçalo] sabia o que essa devoção ocultava" (COUTO, 2006, p.55).

Tal devoção fez com que Nsundi guardasse a imagem escondida nos porões da caravela, onde os escravos habitavam. Trata-se de uma metáfora, já que Nsundi desce a imagem para um nível inferior na caravela, nível em que, justamente, vivem os escravos. Assim, a santa se desloca do Centro para a Margem. No trecho a seguir, observamos que o sincretismo e alteridade se completam na zona de contato:

- És cristão?

Começou por perguntar Manuel Antunes. Depois emendou a pergunta: És crente em Deus?

- Deus não desce lá em baixo.

- Lá em baixo, onde?

- Lá em baixo, onde dormimos nós, os escravos. Já desceu lá?

- Por que razão transportavas Nossa Senhora?

- Ela é Kianda... não é... vocês não sabem... (idem, p.56).

A razão de ser Kianda que ali estava com os escravos e não Nossa Senhora se explica pelo próprio diálogo. A segregação marca a divisão entre os dominadores e seus deuses (Deus judaico/cristão e os santos) e os dominados (escravos e as divindades bantos). Kianda estava entre os seus.

O sincretismo entre Nossa Senhora e Kianda é um instrumento de resgate identitário para Nimi Nsundi, como nos revela a carta escrita por ele a Dia Kumari, a indiana:

Critica-me porque aceitei lavar-me dos meus pecados. Os portugueses chamam isso de baptismo. Eu chamo de outra maneira. Eu digo que estou entrando na casa de Kianda. A sereia, deusa das águas. É essa deusa que me escuta quando me ajoelho perante o altar da Virgem. De todas as vezes que rezei não foi por devoção. Foi para me lembrar. Porque só rezando me chegavam as lembranças de quem fui. (idem, p.113).

\subsection{Kianda ${ }^{1}$, a sereia banto do rio Zambeze}

Uma sereia negra - ao primeiro momento, uma ideia antitética, visto que nosso imaginário caracteriza este ser pela visão eurocêntrica, isto é, branca e loira.

\footnotetext{
1 Do original banto Kyàndà. Há variações presentes nas citações, como Quianda. (Nota do autor do artigo.) 


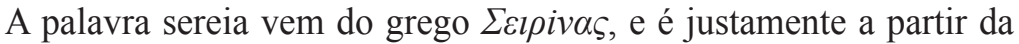
mitologia da Grécia Antiga que este ser, parte mulher e parte peixe, se espalhou para a literatura e demais artes. A tradição diz que eram filhas do rio Aquelôo (Achelous) e de alguma das musas (JEHA, 2007, p.87).

Todavia, as sereias não estão destinadas a serem protagonistas apenas da mitologia europeia. Na África, muitas são divindades aquáticas, cuja iconografia é de uma sereia. Angola, por exemplo, possui suas sereias encantadas, poderosas, influindo para o bem e o mal, com a respeitosa ambivalência popular de amor e medo, como é o caso de Kianda (ou Quianda, por variação).

De origem angolana, Kianda aparece nas obras de grandes escritores, como Manuel Rui, com Rioseco e Um anel na areia; Mãe Materno Mar, de Boaventura Cardoso, em obras de Luandino Vieira, entre outras. Secco (2009, p.2) foca o romance $O$ Desejo de Kianda, de Pepetela, "no qual a divindade é alegoricamente apropriada pelo discurso ficcional. O maravilhoso invade a narrativa e o grito rebelde de Kianda ressoa na dimensão mítica e literária”. A sereia Kianda é relembrada e celebrada por várias partes de Angola, Congo, República Democrática do Congo etc.:

Quianda é a sereia marítima. Vive nas águas salgadas ao redor de Luanda e por toda orla do Atlântico angolano. Sua velha morada era nos rochedos que circundam a fortaleza de São Miguel, entre o Marginal e a Praia do Bispo. Diante da cidade está a ilha de Luanda, Muazanga para os auxiluandas, seus nativos, ligados ao continente por uma larga ponte. Quianda é aí culto antigo para os auxiluandas. Tem uma intérprete, sacerdotisa, devota profissional, a quilamba, açafata em suas festas [...]. (SELJAN, 1967, p.32).

Kianda é o singular da palavra Ianda, ambas oriundas do verbo uanda, em quimbundo, sonhar. Secco revela que a deusa angolana das águas e da vida traz, desse modo, etimologicamente expressa em seu nome, a semântica dos sonhos, já que é função dessas divindades marinhas a comunicação com o mundo ancestral dos antepassados (SECCO, 2009, p.6).

Dutra (2001), evocando o trabalho de pesquisa sobre as sereias africanas de Virgilio Coelho (1997), observa Kianda como a nomenclatura das sereias na região do rio Kwanzà, que banha a cidade de Luanda e avança em direção ao interior do país. À medida que o rio segue seu rumo, a denominação Kitútá fica mais evidente, enquanto Kiximbi é o termo mais antigo (DUTRA, 2001, p. 135). Porém, Seljan, baseada em Câmara Cascudo, vê Kitútá e Kiximbí 
como outras classes de sereias. A Kitútá, moradora dos rios e lagoas, montes e matas, pode viver bem longe da população; já Kixìmbí, que pode ser masculina ou feminina, têm domínio nos rios e lagoas da região. (SELJAN, 1967, p.33).

A pesquisadora ainda continua, revelando que Kianda realmente é uma water genius, antiquíssimas entidades locais valendo como forças materializadoras do próprio elemento. Seu corpo feito d'água é observado no trecho em que Zero Mad Zero relembra seu sonho: "Foi então que outras mãos, feitas de água [...]. Eram as mãos de mulher [...]. E a mulher do sonho vaticinou: As minhas mãos são de água. Sou feita para a sede dos homens" (COUTO, 2006, p.20). Kianda, centenas de anos depois, a partir da colonização, foi reduzida à forma física e aculturada, como a Sereia do Mediterrâneo. Este embranquecimento é observado no mesmo trecho: "Aquelas eram mãos de mulher branca" (ibidem), numa alusão ao sincretismo já existente entre Kianda, ali conhecida como Nzuzu, e Maria.

\subsection{Nzuzu, a negra 'Iara' moçambicana}

“Os Angolas já fraternizam com os Moçambiques”. Estas palavras de Archer (1957, p.136) revelam as condições de troca cultural entre as duas ainda então colônias portuguesas. Devido à formação étnica semelhante, Moçambique e Angola compartilhavam não só na linguagem (tão semelhantes na estrutura, radicais, gramática etc.), mas também nos mitos (ARCHER, 1957, p.213).

Maria Theresa Abelha Alves avalia que os textos que evidenciam os mitos utilizam-nos "como perspectiva para a leitura do mundo, [...], opção política de um narrador que sabe que a verdade não é desnudamento que aniquila o segredo, mas revelação que lhe faz justiça. É, pois, no prisma da magia, do mistério, do segredo que a realidade é refratada". (ALVES, 1997, p.228).

É essa realidade de pluriculturas, miscigenação, sincretismo e resistência cultural que faz com que Mia Couto resgate não só o mito da sereia angolana mas também da moçambicana, Nzuzu. Afinal, o banto, seja de origem angolana, congolesa ou moçambicana, é espiritualista por natureza. É crença geral entre eles que no fundo do mar e dos rios existe uma divindade que exerce influência direta em todos os atos da nossa vida (CASCUDO apud SELJAN, 1967, p.30). 
$\mathrm{Nzuzu}^{2}$ é o nome dado à deusa das águas em Moçambique, um mito muito popular em algumas regiões. Diferente de Kianda, o mito de Nzuzu pertence exclusivamente ao povo shona, patrona de indivíduos como as personagens Mwadia e Lázaro, isto é, sacerdotisas, curandeiros e feiticeiros, ou seja, os nyangas:

The Njuzu holds an important place in the spiritual mythology of the Shona people. Shona folklore, handed down by oral tradition, tells of the many Njuzus which inhabit the lakes and rivers of Mashonaland. It is believed that they are the sacred teachers of traditional healers called N'angas (Nganga). Unlike traditional healers in other cultures, the Shona Nganga is not born with any special abilities. The Njuzu lures a child into the water where they are taught the knowledge of devining and healing. They learn the use of herbs and folk medicines so that when they are returned to the village they may attempt to determine the spiritual explanation of the maladies and misfortunes of their people ${ }^{3}$. (MUKOMBACHOTO, 2009, s/p).

Mukombachoto revela que é Nzuzu quem escolhe crianças para serem suas discípulas. É comum atribuir ainda a ela o desaparecimento de crianças que, transformadas em seus filhos, são levadas a morar no interior das lagoas, rios e mares. Assim, Nzuzu pode ser também a designação para seus discípulos.

Em O outro pé da sereia, a protagonista Mwadia estava destinada a se entregar às águas de Nzuzu e ser uma nyanga. E justamente é esta sua busca ao longo do romance: a busca de uma identidade, principalmente religiosa, a partir do contato com a imagem da Virgem Maria, a Kianda, e agora Nzuzu. Abaixo, a narração acerca do nascimento de Mwadia e sua relação com Nzuzu:

No dia em que Mwadia nasceu, o rio começou a inchar. [...] O Zambeze fechara seu ventre em Cahora Bassa, albufeira começou a tomar forma, as águas atropelando paisagens [...] Nesses dias, logo após o parto, Constança era assaltada por um constante pesadelo. [...] as águas

2 Grafada também como Njuzu ou Nzunzu (Nota do autor do artigo).

3 Nzuzu tem um importante lugar na mitologia espiritual do povo shona. O folclore shona é formado por tradições orais e contos sobre várias Nzuzus que habitam lagos e rios de suas terras. Estes creem que elas são sagradas professoras dos tradicionais curandeiros chamados Nyangas (Nganga). Diferente dos tradicionais curandeiros de outras culturas, os nyangas shonas não nascem com nenhuma habilidade especial. Nzuzu atrai a criança até as águas onde ensinam os conhecimentos da adivinhação e do curandeirismo. As crianças aprendem o uso de ervas e poções, então quando retornam ao vilarejo, podem atender a determinadas explanações espirituais sobre doenças e males de seu povo. (Tradução minha). 
enlouquecidas, começavam a cobrir Vila Longe. A recém-nascida Mwadia estava na igreja, no fundo do vale. Transtornada, Constança acorria para saber da sua menina. [...] Quando chegava à igreja, o nível do rio quase atingira o telhado [...] flutuavam imagens [...] Depois, saía em prantos, na certeza de que perdera a filha. [...] Semanas tinham decorrido quando ela foi surpreendida pela inesperada visão: Mwadia emergia, aflorando viva à superfície das águas. Quando a tomou nos braços, Constança não nutria dúvida: a menina tinha sido tomada por uma divindade das águas. Mwadia passara a ter duas mães, uma da terra, outra das águas. (COUTO, 2006, p.85).

O narrador é incisivo: Mwadia "estava sendo convocada para lidar com os espíritos que moram no rio". (COUTO, 2006, p.85). Talvez esse fora o motivo de Dona Luzmina, a tia de Mwadia, tê-la colocado em um colégio católico nas montanhas do Zimbábue, para afastá-la do destino pagão. Contudo, o discurso cristão das freiras do colégio e o cristianismo exacerbado da tia não convenciam a sobrinha: "Era isso que, agora, eu mais queria ser: um espírito do rio. Ser água na água, ficar longe do mundo, mantendo-se no seu centro". (COUTO, 2006, p.85).

A tia não se conformava com a ideia "pagã" da sobrinha em se converter numa Nzuzu: "Se ela regressasse naquelas férias, não teria maneira de recusar: seria enviada para a lagoa de Mbenga e se converteria numa Nzuzu, um espírito das águas. Submergiria para o fundo do lago e ali viveria meses consecutivos sem aflorar à superfície”. (COUTO, 2006, p.85). Contudo, as ameaças da tia em separar Mwadia de Zero, culpando-o por essas ideias, mudou a mente de Mwadia, que retornaria dois anos depois para Vila Longe a fim de encontrar o amado e não mais a serviço dos espíritos. O mesmo discurso é citado por Lázaro acerca do batismo de Mwadia:

Era a primeira vez que o curandeiro Lázaro narrava o episódio do baptismo tradicional de Mwadia. Fora ele que a baptizara, levara-a ao rio Mussenguezi. No momento em que submergiu, a pequena Mwadia começou a entrar em delírio, possuída por um espírito todo-poderoso. De repente, sucedeu o inesperado: as ondas levantaram-se e o rio tornou-se caudaloso a ponto de ele próprio, o cerimoniante Lázaro, fugir e deixar a menina abandonada. Quando voltou, já não a encontrou. Dias depois, Mwadia foi encontrada na margem, envolta em folhagens que a corrente arrastava. (COUTO, 2006, p.273). 
A deusa das águas moçambicanas prefere as águas doces ao invés do mar, como Kianda. Nzuzu vive nas águas de córregos, rios, nascentes e lagos, e traz consigo uma cobra chamada Nyoka, que se liberta quando a água límpida se torna suja, espalhando maldades e feitiços. Uma mostra das preocupações ambientais dos africanos, já que são essencialmente panteístas.

A paisagem moçambicana é pincelada com inúmeras imagens de turvos rios e lagoas. O Zambeze é a $13^{\mathrm{a}}$ maior bacia hidrográfica do planeta, abarcando vários afluentes. Nesta pintura de Mia Couto, personagens percorrem as águas a favor e contra a corrente. Em determinado momento da narrativa, a brasileira Rosie, recém-chegada a Vila Longe, espreita as águas e questiona se ali haveria crocodilos, hipopótamos e monstros. Casuarino responde que ali habitavam espíritos, e que havia uma deusa que morava nas águas (COUTO, 2006, p.140). "Eu sei, interrompeu excitadamente a brasileira. Eu li sobre essa crença. Na África Ocidental, chamam essa deusa de Mama Wati. - Aqui chamamos-lhe Nzuzu". (COUTO, 2006, p.141). Southman, parceiro de Rose, também observa: "Essa é Mama Wati, the mother of water. É assim que lhe chamam os negros da costa atlântica. Southman falava dessa sereia que os africanos fantasiaram a partir da imagem de Nossa Senhora - [...] Mama Wati, mãe das águas”. (COUTO, 2006, p.193).

Mama Wati é um bom exemplo sobre a diáspora que divindades sofrem durante o processo colonizatório. Seu nome, em africâner, nos leva a crer que muitas divindades aquáticas foram sincretizadas com a grande Mãe ou com Maria, recebendo nomes híbridos - Mama Wati, provavelmente oriunda do africâner, um desvio de Mommy Water, Mãe d'Água.

Voltando à conversa de Rose e Casuarino, este discorreu que nas profundezas das águas morava Nzuzu, uma divindade que levava moças aos fundos lodosos. E ali lhes ensinava a arte de ser peixe e os sortilégios da adivinhação, até que um dia emergiam e seguiam o destino de serem uma nyanga. Por mais 'cristãos' que os habitantes de Vila Longe fossem, "olhavam a estátua [de Nossa Senhora] e viam nela o espírito de Nzuzu”. (COUTO, 2006, p.242).

Nzuzu é uma das poucas divindades moçambicanas que necessita de uma iniciação de um indivíduo, a fim de perpetuar seu culto. Situação semelhante acontece com a divindade aquática Yemonjá (Yá òmó èjá / mãe dos filhos peixes) dos iorubás. Aliás, os estudos de Câmara Cascudo (2001) sobre o culto das sereias em Angola, Guiné e Moçambique basearam-se na tentativa de documentar e identificar os sincretismos de Yemonjá, muito cultuada no Brasil, com identidades de outros povos africanos, como aliás é projeto seu. 
Percebe-se então que, a partir da chegada da missão de Dom Gonçalo em 1560 a Moçambique, Nzuzu assume o lugar de Kianda. "Não vê que esse Silveira é filho de Nzuzu, a deusa das águas?” (COUTO, 2006, p.313), diziam os nativos, trazendo a mesma relação sincrética com Nossa Senhora, nosso próximo foco.

\subsection{Nossa Senhora, a virgem mãe judia de todo o cristianismo}

Maria (Maryam bat Hannah), que se acredita ter nascido na Galileia, a partir de 15 a.C., era a mãe de Jesus de Nazaré, segundo o Novo Testamento. A Igreja Católica a denomina também co-redentora da humanidade, virgem, imaculada e assunta. Maria é uma personagem bíblica duplamente colonizada. Mulher, adolescente e judia, que vivia na cidade de Nazaré, colonizada pelo Império Romano. Engravidara de Jesus, ainda noiva de um homem muito mais velho, José (Yossef).

O culto à Maria iniciou-se com a proclamação da Mater Dei em Éfeso, no ano de 431, posterior ao culto dos mártires (AUGÉ, 1998, p.330). Com o tempo, a Europa, já dominada pelo cristianismo, ajoelhar-se-ia perante Nossa Senhora. As nações imperialistas católicas, como Portugal, por exemplo, acreditavam ser a colonização obra de Deus e abençoada pela mãe, Maria. Conforme Boff, "a figura de Maria fazia parte até mesmo da política de Estado". (BOFF, 1944, p.9). Nossa Senhora da Conceição tornar-se-ia a padroeira de Portugal e, consequentemente, a padroeira dos avanços sobre o mar. Souza (2008) revela, em seu artigo Virgem Imperial: Nossa Senhora e império marítimo português, que as representações de Maria facilitariam a catequese e, assim, a conversão dos infiéis e gentios. Dentre as várias faces marianas, destacavam-se na colonização Nossa Senhora da Conceição e Nossa Senhora do Rosário (p.30).

A fé dos navegadores em Maria é observada nos nomes das caravelas portuguesas, como Santa Maria, de Cabral, e Nossa Senhora da Ajuda, caravela do romance citado, que, aliás, fora a mesma que trouxe Tomé de Souza, em 1549, ao Brasil. Da expansão marítima portuguesa nasce o culto a Nossa Senhora da Boa Viagem e crescentes boatos de aparições. No Brasil, Nossa Senhora da Graça foi a primeira manifestação da Virgem Maria, vista pela índia Paraguaçu, na época do descobrimento (CRIVELLARO, 1998, p.41). 
As relações de Nossa Senhora com a colonização têm seus fundamentos. Nas idas e vindas das caravelas com "Maria", por vezes a mãe de Jesus ficava mais famosa que o próprio filho. Dessa forma, a cada nação colonizada Nossa Senhora foi fortemente relacionada ao culto das grandes mães ou deusas da Antiguidade (ATIENZA, 1995). Um dos motivos seria a própria maternidade $\mathrm{e}$, por conseguinte, a fertilidade. Com os encontros provindos do contato com os povos colonizados pelos portugueses, o sincretismo entre Nossa Senhora e outras divindades foi constante. A devoção a Nossa Senhora e a assimilação da crença do colonizador aconteceram de forma eficaz, haja vista que Maria é a mais importante figura feminina do catolicismo.

Para entendermos a relação entre Maria, Kianda e Nzuzu, observemos os dizeres de Berkenbrock (1998), que enfatiza que os santos e as divindades não foram escolhidos ad libitum, mas por fortes critérios de identificação. Nsundi, em sua carta de adeus à Dia Kumari, indiana companheira de caravela, confirma a lógica do sincretismo entre a imagem de Maria e Kianda, quando diz: "Quando a olhei de frente confirmei que era ela, a Kianda: os cabelos, a pele clara, a túnica azul. O que sucedeu é que nossa deusa ficou prisioneira na estátua de madeira dos portugueses". (COUTO, 2006, p.208).

Nossa Senhora da Graça, cuja iconografia revela manto azul, cabelos longos soltos e pés à mostra é a representação que costurou a imagem sincrética dela - Kianda.

Essa trajetória de identidades da Virgem Maria observada por Mwadia: "Você já foi Santa. Agora, é sereia. Agora, é Nzuzu". (COUTO, 2006, p.329), reforça a ideia de uma África miscigenada, híbrida, que contraria os pressupostos apolíneos e homogêneos da cultura dominante. A valorização do sincretismo e das constantes passagens que evidenciam as várias faces de uma divindade revela o poder subversivo da "polifonia religiosa". Bhabha crê que essa mistura faz com que o sujeito (pós-) colonial exponha seu ponto de vista contra a 'Outra' visão, mantendo uma abertura que reverte as estruturas de dominação cultural. "Um momento ativo de desafio e resistência contra o poder colonial dominante [...] negando a cultura imperialista imposta". (BHABHA apud YOUNG, 1995, p.23). Desta forma, quando o sincretismo é invertido pelas personagens, isto é, Nossa Senhora "é” Kianda, “é” Nzuzu, os colonizados subvertem o ícone católico e consequentemente o discurso dominante. A própria capa da versão brasileira do romance atesta tal perspectiva, quando a figura da Imaculada Conceição é "maculada" com atributos de seres pagãos, 
no caso uma cauda de sereia. Sintetiza-se esse amálgama nas palavras de Tânia Macedo: "Ora, é justamente esse jogo em que abundam as dúvidas sobre a figura da Kianda e a fé na mesma, que se questiona mais profundamente a realidade e a ficção". (MACEDO, 2009).

A diáspora da imagem de Maria é um símbolo metonímico da própria diáspora do colonizado - transculturando-se, aculturando-se, transmutando-se. O sincretismo só atesta que a religião é a instituição que mais resiste ao poderio colonial, sempre em mutação, a fim de não se perder nos mares de Angola, nos rios de Moçambique ou nas terras da Galileia.

\section{Referências}

ALVES, M. O Desejo de Kianda: crônica e efabulação. Scripta - Revista do Programa de Pós-graduaçao do CESPUC. Pontifícia Universidade Católica - MG, v.1, n.1, 1997.

ARCHER, M. Terras onde se fala português. Rio de Janeiro: Casa do Estudante CEB, 1957. ATIENZA, J. G. Os santos pagãos: deuses ontem, santos hoje. São Paulo: Cone, 1995. AUGÉ, M. Culto aos santos e Maria. In: . Liturgia. São Paulo: Ave Maria, 1998.

BERKENBROCK, V. J. A experiência dos orixás. São Paulo: Vozes, 1998.

BOFF, C. Maria na cultura brasileira. Petrópolis: Vozes, 1995.

BOFF. L. Igreja: carisma e poder. São Paulo: Ática, 1994.

BRUMANA, F. G.; MARTINEZ, E. G. Marginália sagrada. Campinas: Unicamp, 1991.

CÂMARA CASCUDO, L. Sereias de Angolas. In: Made in África. 5.ed. São Paulo: Global, 2001.

CHABAL, P. Vozes moçambicanas: literatura e nacionalidade. Lisboa: Vega, 1994.

CHAIM, I. O diabo nos porões das caravelas. Juiz de Fora: UFJF/ Ed. Pontes, 2003.

COUTO, M. O outro pé da sereia. São Paulo: Companhia das Letras, 2006.

CRIVELLARO, D. O triunfo de Maria. Época, ano 1, n.31, 21 de dez 1998. Rio de Janeiro: Ed. Globo, 1998.

DUTRA, R. L. As águas e suas metáforas de libertação e renovação: alguns aspectos nas obras de Mia Couto e Pepetela. In: CONGRESSO INTERNACIONAL DA ALADAA CULTURA, PODER E TECNOLOGIA: África e Ásia face à globalização. 2001. Rio de Janeiro. Anais... Rio de Janeiro: Educam, 2001. p.745-748.

JEHA, J. Monstros e monstruosidades na literatura. Belo Horizonte: UFMG, 2007.

MACEDO, T. Um anel na areia, uma narrativa que se afasta do dogmatismo. Disponível em: <http://www.uea-angola.org/artigo.cfm?ID=48>. Acesso em: 28 out. 2009. 
MAGALHÃES, A. C. M. Sincretismo como tema de uma teologia ecumênica. Ecumenismo: estudos da Religião, n.14, ano XII: UMESP, 1998, p. 49-70.

MUKONYORA, I. Women and Ecology in Shona Religion. Word \& World, v. 19, n. 3, 1999.

SECCO, C. L. T. R. A importância da literatura e das artes plásticas no contexto da cultura angolana. Conferência apresentada no Fórum dos Angolanistas - UERJ, 03/09/2005. Disponível em: <www.letras.ufrj.br/posverna/docentes/62671-1.pdf> Acesso em: 23 out. 2009.

SELJAN, Z. A. O. Iemanjá e suas lendas. Rio de Janeiro: Record, 1967.

SOUZA, J. B. A. Virgem Imperial: Nossa Senhora e império marítimo português. Luso-Brazilian Review, v. 45, n.1, 2008.

VALENTE, W. Sincretismo religioso afro-brasileiro. São Paulo: Brasiliana, 1977.

YOUNG, R. J. C. Colonial desire: hybridity in theory, culture and race. London; New York: Routledge: 1995.

Recebido para publicação em 31 de março de 2011. Aceito para publicação em 24 de novembro de 2011. 